\title{
Primate Populations and Their Interactions with Changing Habitats
}

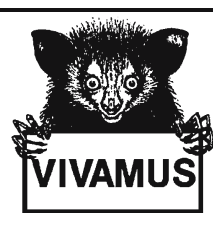

\author{
Gilbert M. Isabirye-Basuta • Jeremiah S. Lwanga
}

Received: 12 September 2007 / Accepted: 18 October 2007 /

Published online: 15 February 2008

(C) Springer Science + Business Media, LLC 2008

\begin{abstract}
Given that $90 \%$ of nonhuman primates depend on tropical forests, the most effective way to conserve them must emphasize the conservation of tropical forest habitats. To achieve this effectively, we need to address root causes of forest disturbance in developing nations: poverty, high population growth rates, crippling foreign debts, and the overdependence on tree and land resources. Moreover, it is now generally accepted that most primate populations will in future live in modified forest habitats. Studies of how primate populations respond to forest habitat modifications are therefore critical to future primate conservation. Currently most studies of primate responses to forest habitat alterations are difficult to interpret owing to differences in research methods and lack of information on the past histories of the modified forests. We review potential factors that may have to be considered while evaluating primate responses to forest habitat changes such as degradation and fragmentation.
\end{abstract}

Keywords habitat $\cdot$ modifications $\cdot$ primates $\cdot$ responses

\section{Introduction}

Primate populations, like those of other organisms, face the challenge of coping with the dynamics of their habitats because habitats are continually changing and primates must adapt to changes in order to survive; failure to adapt dooms species to extinction. Because most primate species live in tropical forests (Chapman et al. 2006a; Lovett

G. M. Isabirye-Basuta $(\triangle)$

Department of Zoology, Makerere University, P.O. Box 7062, Kampala, Uganda e-mail: head@zoology.mak.ac.ug

J. S. Lwanga

Makerere University Biological Field Station, P.O. Box 409, Fort Portal, Uganda

e-mail: jeremiah.lwanga@yale.edu 
and Marshall 2006; Mittermeier and Cheney 1987), protection of forest habitats should be high on the agenda for primate conservation. However, conserving the world's tropical forests is not an easy task for several reasons. First, the forest habitats are mostly fragmented and scattered in many different countries. Hence international organizations that are key players in conservation need to work with many national governments, each with its own priorities and problems. Second, most, if not all, tropical forests that are rich in primate diversity are in economically poor nations. For example, 9 of the 15 richest countries in terms primate species are in Africa (Chapman et al. 2006a). Some of the nations are not only poor but also politically unstable. It is difficult to expect such countries to make forest protection a high priority. Even if foreign assistance were available, it is difficult to deliver during war. Third, the population growth rate in developing nations, particularly in Africa, is high and most people depend directly on natural resources such as land for survival; therefore, the need to clear forests to create land for agriculture is high. This does not augur well for forest protection. Fourth, most developing nations are overburdened with foreign debts that compel national governments to encourage exploitation of forests (Stuart et al. 1990, cited in Chapman et al. 2006a). Though lenders have forgiven foreign debts for some developing nations, it is unfortunate that the nations have not invested the money saved in sectors that boost economic growth in the short term, without which future borrowing may be inevitable. Given the problems, it is clear that saving forest habitats will need full commitment from governments and people of poor nations, international organizations, and governments and people of rich nations.

We emphasize that not all habitat changes are due to human activities. Therefore, one can broadly divide habitat change into 2 categories: natural and human-induced. Natural habitat changes include changes as small as a wind throw of an important food tree; tree dieback due to cohort senescence; and vegetation changes caused by large herbivores, landslides, hurricanes, and drought-related tree mortality. All of these changes may affect primate populations negatively. However, some natural habitat changes such as forest colonization can boost populations of some primate species.

The second category, human-induced habitat changes, includes factors such as forest degradation (mainly through mechanical logging), forest fragmentation, introduction of exotic species, and deforestation, i.e., replacement of forests with lands dominated by human activities, such as agriculture. Understanding how primate populations respond to the habitat changes is complicated by the fact that in nature, the factors are not isolated; some are interrelated while the effects of others are aggravated by external factors. For example, while the removal of a few trees via logging may not have a serious impact on primate populations, the outcome will be different if logging occurs on a large scale and immigration of people follows.

\section{Types of Habitat Change}

The main human-induced forest habitat changes include mechanized logging, forest fragmentation, introduction of exotic plant species, and deforestation. Natural changes in forest canopy cover/tree specific composition may be a result of tree dieback, droughts, or climatic change, or all of them. 


\section{Primate Responses to Forest Habitat Changes}

\section{Studies of Responses to Logging and Their Limitations}

Researchers have conducted many studies to examine responses of primate species to logging in tropical forests (Johns and Skorupa 1987). Chapman et al. (2000, 2003), Mitani et al. (2000), Plumptre (1996), Plumptre and Reynolds (1994), and Struhsaker (1997) have summarized most recent work. However, many of the studies give contradicting findings. For example, of the 38 tropical primate species Johns and Skorupa (1987) considered, 71\% declined after logging, while 22\% increased and $6.7 \%$ were apparently unaffected. Though some of the differences may reflect differences in feeding guilds of the primates concerned, e.g., folivores vs. frugivores, in general, the importance of such comparisons is limited by factors such as differences in field methods used, in primate specific compositions and densities, logging intensity and incidental damage to forest trees, vegetation types adjacent to logged areas, forest age, tree specific composition and density before logging, and natural variation in habitat types within the forest and in densities of large terrestrial herbivores. The factors can influence results from studies that attempt to monitor responses of primates to logging and may account for why conclusions from several studies have been different even when the same primate species are considered.

Ideally, understanding how primate populations respond to logging would require a prelogging study to provide baseline data against which one can measure any change in primate populations after logging. Practically, this has been impossible because logging companies are not obliged to inform primatologists or conservation groups about their activities. Second, getting a good understanding of the primate population in an area to be logged requires several years of observations, which may be incompatible with logging schedules. Consequently, the most practical way to study the responses of primate populations to habitat changes caused by logging has been via comparisons of primate populations in logged areas with the ones in adjacent unlogged parts of the forest. This may be fair enough, assuming that before the logging, the logged and unlogged forests were similar in primate populations and habitat conditions. However, it may not always be the case, which may account for contradictory results on the responses of primate populations to logging.

It is unfortunate that the history ( $>200 \mathrm{yr}$ ) of most tropical forests is not known; yet primate populations fluctuate owing to long-term historical factors. Without knowledge of the history, researchers can erroneously attribute such fluctuations to logging if the latter coincides with fluctuations in primate communities. For example, at Ngogo, Kibale National Park, the populations of red colobus and blue monkeys are declining (Mitani et al. 2000) in spite of the fact that no logging has occurred in the area. The 2 species seem to be responding to different natural phenomena; decline of the blue monkey population seems to be the consequence of competitive exclusion from other forest primates. Blue monkeys are a generalist species that does not compete well with old growth specialists (Struhsaker 1978), which suggests that they do poorly in old growth forests, and as the forest matures further, their populations will decline and possibly disappear. In support of this hypothesis, Chapman et al. (2000), working at Kanyawara, $10 \mathrm{~km} \mathrm{NW}$ of Ngogo in 
the same forest, detected a significant decline in the density of blue monkey groups in the unlogged old growth forest over 28 years.

Long-term historical factors can have a significant bearing on the current population sizes of some primate species, which in turn can impinge on other species. For example, the old growth forest at Ngogo, though it appears virgin (Nummelin 1990), harbors grinding stones and shards of pottery that indicate that people once lived there. Decorations on the pottery shards are typical of the period between 200 and 400 b.p. (Peter Bisaso, pers. comm.). The forest at Ngogo supports a high density of chimpanzee food tree species, particularly Ficus mucuso and Pterygota mildbraedii, that appear to establish well in disturbed areas. Also, the 2 species were of high spiritual significance and never cut by people, and apparently took advantage of the abandoned gardens and established in large numbers when people left. The high abundance of food for chimpanzees at Ngogo, which is influenced by historical factors, seems to be a major factor that accounts for the high population density of chimpanzees at Ngogo. With about 145 individuals, the Ngogo chimpanzee community is the largest ever recorded in the wild (Mitani and Amsler 2003; Watts et al. 2006; Watts and Mitani 2001). Again from Ngogo, a recent study (Teelen 2005) indicated that the decline of red colobus population is the result of predation by chimpanzees. Unfortunately, few forest sites have been studied in such detail and such responses can confound the ones caused by logging if the 2 phenomena coincide.

\section{Influence of Adjacent Vegetation Types on Primate Responses to Logging}

While evaluating responses of primate populations to logging activities, it is important to consider the possible effects of habitat types that surround their preferred habitats. Primates respond to changes in the surrounding habitat types as well, which may confound responses caused by logging especially if logging operations and primate movements to or from the neighboring vegetation types coincide, or major floral changes such as forest colonization occur in areas adjacent to the logged forest after the logging.

For example, Kibale is a patchwork of vegetation types including tropical moist forest, grasslands, and colonizing forest. Also, at the time of logging, exotic tree plantations were present. In addition, logging occurred when the population of large herbivores was at its lowest. The low density of large herbivores, and possibly reduced frequency of fires, could have triggered the rapid colonization of grasslands by forest that is evident in many parts of the park today (Lwanga 2003). Unfortunately, researchers did not recognize and did not investigate the potential influence of forest colonization on primate populations in the forest in early studies (Chapman et al. 2000; Struhsaker 1997). At Kanyawara, Chapman et al. (2000) reported declines in relative abundance (number of groups seen per $\mathrm{km}$ ) for several primate species both in the unlogged and logged forest: during 1970-1997 for the unlogged forest and 1980-1997 for the logged compartments. Species that declined appreciably in the unlogged forest were red colobus, black-and-white colobus, blue monkeys, and redtailed monkeys. In the lightly logged forest, only red colobus declined significantly; in the heavily logged forest, all species except mangabeys declined significantly.

Given that declines in the relative abundance of some primate species also occurred in the unlogged forest, it is difficult to attribute all the declines elsewhere to 
logging. One attribute common to all forest compartments that Chapman and colleagues used is that each one of them is adjacent to colonizing forest and groups of monkey species, particularly red colobus, black-and-white colobus, and red-tailed monkeys are frequently sighted in the colonizing forests. Some of the declines reported at Kanyawara were apparently due to ecological release because, as more habitat is created by forest colonization, either some monkey groups move out of the old growth forest or expand their home ranges. Such changes are difficult to detect from fixed census routes. Therefore, future investigations into the effects of the logging effects of the 1970s on the primate populations at Kanyawara should take forest expansion into consideration because it is clear that this form of habitat change affects some primate species. In a study focusing on red colobus in Kibale, Chapman et al. (2002) demonstrated that the species is very flexible in terms of plant species and parts exploited for food. Perhaps it is this flexibility in dietary requirements that permits them to inhabit colonizing forests. The same may be true for black-andwhite colobus and red-tailed monkeys.

\section{Influence of Tree Specific Composition on Primate Responses to Logging}

The tree specific composition in a forest can influence the way primates respond to logging. Therefore, in any study attempting to assess the effects of logging on primate populations, it is important to try to get detailed descriptions of the logged forest before logging. Information on the tree species removed and the amounts removed is vital because not all trees are equally important as food sources for primates. Removal of nonfood tree species may have little or no impact on the primate community. A good example is a study conducted in the Budongo Forest, Uganda, only $c a .100 \mathrm{~km}$ from Kibale. Whereas results from Kibale suggest that blue monkeys and red-tailed monkeys decline after logging, in Budongo (Plumptre and Reynolds 1994), the species increased 50 yr after the logging. As in Kibale, black-and-white colobus were favored by logging (Plumptre and Reynolds 1994). It is important to note that only 4 species of mahogany accounted for the bulk $(65 \%)$ of the trees removed from Budongo (Plumptre 1996). The species are of limited importance to primates as food sources (Struhsaker 1997). After logging in Budongo, Cynometra alexandri, a species that tends to form a monodominant forest and is of little importance to the primates (Struhsaker 1997), was poisoned with arboricides (Plumptre 1996). The conditions favored the establishment of a mixed-species forest, which is a more suitable habitat for the frugivorous blue monkeys and red-tailed monkeys. Without detailed information on tree specific composition in the Budongo Forest before logging, results from the forest seems to contradict directly the ones from Kibale and would give the impression that logging is always good for primate conservation. Results from the study should caution against generalizing conclusions from one area to another without close scrutiny.

\section{Influence of Primate Diets on their Responses to Logging}

Differences in diets among primate species may in part account for the lack of consistent results from studies attempting to investigate responses of primate populations to logging. For example, dietary specialists and generalists may not be 
affected by logging in the same way. Similarly frugivorous and folivorous species are likely to respond differently to logging. A study from Budongo (Fairgrieve and Muhumuza 2003) showed that the consumption of fruit by blue monkey groups in the logged forest was high and more consistent than that of blue monkeys inhabiting the unlogged forest. The differences in feeding scores between monkey groups inhabiting logged and unlogged forest were the result of differences in food availability, in terms of tree specific composition, abundance, and phenology (Farigrieve and Muhumuza 2003). Results from the study lend support to an earlier study (Plumptre and Reynolds 1994) that suggests that in the Budongo Forest, logging improved the habitat for blue monkeys.

At Kanyawara, Kibale Forest, the only primate species that lives at higher densities in the logged forest than the unlogged forest is the folivorous black-and-white colobus (Chapman et al. 2000; Skorupa 1986). Densities of some of the important food tree species for black-and-white colobus, such as Celtis durandii, C. africana, Olea (welwitschii) capensis, Balanites wilsoniana, and Premna angolensis (Oates 1974) are very high in the logged forest (Kasenene 1987), which suggests that logging can be beneficial to black-and-white colobus. However, some groups of red colobus also rely on some of the species, yet they do not do well there, suggesting that food availability alone does not explain all the changes in primate populations after logging.

At Tekam, Malaysia, breeding rates for most primate species declined $6 \mathrm{yr}$ after the logging event (Johns 1992), suggesting the primates were affected negatively by logging. Conversely, the occurrence of 1 species, Macaca fascicularis, that specializes in high-productivity secondary forests increased after logging (Johns 1992). It therefore appears that the diet of primate species and the plant specific composition and abundance in the regenerating forest play an important role in the response of a primate species to logging.

\section{Influence of Large Herbivores on Primates Responses to Logging}

One of the major impacts of logging on primate populations is the reduction in food availability. Therefore, in situations in which logging can stimulate or is followed by regeneration of food species, the impact should be minimal. Apparently, the differences in tree species removed from Budongo and Kibale are not the only ones to account for differences in primate populations in the 2 forests. Whereas regeneration of several tree species occurred after logging in Budongo (Plumptre 1996), studies from Kibale (Kasenene 1987; Lawes and Chapman 2006; Nummelin 1990; Paul et al. 2004; Struhsaker 1997; Struhsaker et al. 1996) strongly suggest that elephant browsing in the logged areas suppresses regeneration. Logged areas in Kibale are dominated by thick tangles of herbaceous vegetation (Struhsaker 1997). In Budongo, elephants were eliminated before 1970 (Paterson 1991). Suppressed regeneration of trees in Kibale may in part explain the slow recovery of primate populations there.

\section{Response of Primates to Forest Fragmentation}

Unless the current rate of forest conversion is halted, it is inevitable that more and more primate populations will live in isolated fragments. Unfortunately, the factors 
that allow primate species to persist in forest fragments are poorly understood, which makes it difficult to devise ways to conserve primates in fragmented habitats. Factors that researchers believe determine persistence or extinction in forest fragments, e.g., dietary flexibility/specialization, fragment size, and distance between fragments, do not seem to explain all situations. Even within the same species, the responses of primates to fragmentation differ. For example, mangabeys do not live in any of the forest fragments around Kibale National Park, but they are common in forest fragments in the Victoria Basin. Similarly, blue monkeys at Kibale do not occupy forest fragments, yet around Budongo they are present in some of the forest fragments. Blue monkeys are distributed over a wide range from southern Sudan to South Africa as different subspecies typically living in fragmented and disturbed habitats (Lawes 2002). However, in a study in South Africa, Lawes (2002) demonstrated that not all forest fragments were occupied by blue monkeys, even those that appeared to be suitable habitats. Twinomugisha (2007) found a similar situation for golden monkeys (Cercopithecus mitis kandti) in Mgahinga National Park, Uganda. Golden monkey populations were limited to the bamboo zone, though other types of habitat were available, The observations suggest that some other factors limit dispersal into unoccupied fragments. Chapman and Peres (2001) suggested that the survival of primates in fragments might be determined by factors in the matrix that surrounds the forest fragment. However, the factors remain unknown but researchers need to investigate them if fragmented primate populations can be conserved as metapopulations.

In addition to extinction risks associated with small populations, primate populations inhabiting forest fragments face the danger of continuous habitat degradation. Forest fragments are typically surrounded by human settlements. In the majority of developing countries, people depend on wood fuel for cooking and building poles. Forest fragments that primates occupy are not exempted from exploitation for such resources, which may have deleterious effects on the primate populations living there. For example, studies on primates inhabiting forest fragments near Kibale National Park revealed that 3 of the 16 fragments primates occupied in 1995 were exploited to the point that they were no longer occupied by the year 2000 (Chapman et al. 2003, 2006b). In another study, Gillespie and Chapman (2006) found that the index of forest patch degradation and the presence of humans strongly influenced the prevalence of parasitic gastrointestinal nematodes in red colobus, which suggests that as forest fragments become smaller, and frequency of contact between humans and nonhuman primates becomes higher, transmission of diseases and pathogens will be a very likely consequence. The risk of disease transmission between humans and nonhuman primates is even higher for the great apes because the latter are phylogenetically closer to humans than other primates are. For example, in Gombe National Park (which is essentially a forest fragment), Tanzania, 14 chimpanzees from the Kasekera community died of suspected pneumonia between 1968 and 1987; another 11 chimpanzees in the neighboring Mitumba community died of a respiratory disease in 1996 (Reynolds 2006). In the Virunga Volcanoes, $\geq 81 \%$ of the gorillas in 7 groups used for research and tourism suffered from an influenza-like disease and 6 adult females succumbed to the disease during 1988 (Reynolds 2006). The observations highlight the dangers to which nonhuman primates can be exposed as forests are fragmented further. However, 
disease transmission can occur in both directions, though nonhuman primates are at greater risk than humans are. Diseases in humans can be detected faster and controlled or eliminated, whereas in wild nonhuman primates it can be an insurmountable task. Moreover, many primate species live in small populations, in which case a single outbreak can eradicate the entire population. On several occasions, outbreaks of Ebola in humans have been linked to wild primate sources (Leroy et al. 2004; Rouquet et al. 2005; Vogel 2003). Infections of laboratory and zoo workers and bushmeat hunters by simian immunodeficiency viruses (SIV) and other simian retroviruses have occurred (Wolfe et al. 2004). HIV/AIDS might be the result of cross-species transmission of SIV to humans (Peeters 2004; Sharp et al. 2004). Accordingly, by increasing human contact with nonhuman primates via forest fragmentation, we also run the risk of exposing ourselves to new diseases. However, more recent literature suggests that we should be cautious in accepting the aforementioned scenario (Chapman et al. 2006c).

\section{Response of Primates to Deforestation}

Given that the great majority of primates are dependent on forests, deforestation is perhaps the most serious threat to primate survival globally. It is estimated that without human impacts, $30 \%$ of Uganda's land area would be under forest cover, but owing to deforestation, at present forests represent only $3 \%$ of the land area (Karlowski 2006). Evidence from pollen records indicates that deforestation started ca. 2200 yr ago (Taylor 1990 cited in Karlowski 2006). Perhaps the impact of the early deforestation on the primate populations was not so great because human population density was very low, which allowed forests time to recover.

It is important to emphasize that forests have the capacity to recover after clearance because nowadays, at least in Uganda, degraded forest reserves tend to be given away for conversion. This is particularly true for the small forest reserves in the Victoria Basin; but even the large ones such as Mabira Forest Reserve are not safe (Masmbuko 2005). For a forest to regenerate on degraded lands, there must be a nearby intact forest to act as a seed source, and animal seed dispersing agents, and the land must be protected from further disturbance (Karlowski 2006; Lwanga 2003). Researchers have rarely evaluated the usefulness of secondary forests regenerating on degraded lands for primate conservation, but the few attempts to do so provide encouraging results. For example, in Costa Rica, Fedigan and Jack (2001) reported the recovery of howlers (Allouatta palliata) and capuchins (Cebus capucinus) on former ranchlands in only $28 \mathrm{yr}$ after cessation of active management of the lands. In Kibale, Lwanga (2006) encountered all 8 diurnal primate species in forest patches regenerating in former grasslands and sighted black-and-white colobus more frequently in the colonizing forest. Though not focusing on primates, DeWalt et al. (2003) demonstrated that $\leq 70 \mathrm{yr}$ after the abandonment of the land on Barro Colorado Island, the secondary forest resembled the old growth forest in many structural attributes. In addition, understory fleshy fruit availability was higher in the secondary forest than in the old growth forest (DeWalt et al. 2003). Their observations demonstrate the resilience of tropical rain forests and argue against giving away degraded forest reserves for permanent conversion.

Springer 
In Cowlishaw's (1999) analysis on primate diversity on the African continent, primate species exhibited the classic species-area relationship $\left(S=c A^{z}\right)$ across countries, which suggests that one can predict the number of primate species that are likely to become extinct as a result of deforestation in a country. In fact, no primate species has gone extinct in any country in the past $50 \mathrm{yr}$ in spite of massive deforestation. However, this is no reason for complacency because Cowlishaw based the analysis on presence/absence of primates and did not consider if the populations in the countries were viable or not, and because within a country, primates do not live as a single population, but instead occur in isolated pockets of forests. It is therefore possible that a primate species recorded as extant in a country as a whole may actually have gone extinct in some forests of its historical range. The primate fauna of Kibale and Itwara Forests in Uganda are illustrative cases. Whereas the 2 forests are separated by only $10 \mathrm{~km}$ and probably were contiguous historically, in Itwara, only $15 \%$ the size of Kibale, the primate community is impoverished. Two, perhaps 3 forest primate species, viz., red colobus [Procolobus (Piliocolobus) pennantii tephrosceles], mangabeys (Lophocebus albigena), and probably, l'hoesti monkeys (Cercopithecus l'hoesti) that are extant in Kibale are absent in Itwara, most likely due to extinction because of Itwara's size (Struhsaker 1981).

Cowlishaw (1999) concluded that the fact that no African country has lost a single primate species in spite of massive deforestation during the past $50 \mathrm{yr}$ represents a time lag between deforestation and extinction of primate species. He refers to the time lag as extinction debt, which could be as high as $50 \%$ (4-8 species) of the extant species for some countries. Given that Cowlishaw based his analysis on historical deforestation and did not include other factors such as the current deforestation and hunting, the extinction threat could be much worse than he predicted. Forest contraction is one of the expected consequences of global warming. Therefore, if global warming actually takes place, extinction threats for forest primates may be high.

One possible explanation for specific persistence or at least the delayed extinctions as a result of historical deforestation is ecological flexibility in habitat use, behavior, or diet. Some primates can survive in several different habitat types, allowing them to survive in degraded habitats. Arboreal species that are comfortable traveling on the ground can avoid extinction by using an archipelago of forest patches as one home range provided the distances between patches are not too long. In southern Amazonia, Michalski and Peres (2005) found that 2 primate species, brown capuchins (Cebus apella) and titi monkeys (Callicebus moloch) that have wide dietary breadths were less sensitive to reduction in forest patch size than specialized feeders were. Also, deforestation does not necessarily result in areas devoid of vegetation; in most cases, forests are replaced with agricultural crops and tree plantations. Some primates are capable of including the introduced plant species in their diets. Therefore, some primate species that persist in forest fragments are actually obtaining some dietary requirements in areas larger than the forest patches they occupy. Agricultural crops are selected for their high nutritional values and have the capacity to attract forest primates. The situation results into human-primate conflict because of crop-raiding.

Perhaps the single most important factor that renders primates more likely to go extinct as a result of habitat loss is the limited geographical range for many primate species. Simberloff (1992) noted that in spite of the massive deforestation in the 
eastern United States of America over the last 2 centuries, only 3 bird species have gone extinct, while the majority of birds have persisted in the remaining $1-2 \%$ of the original forest habitat. He attributed the high persistence of the North American birds to their large geographical ranges, which enabled them to avoid extinction from habitat destruction. Further, the ability to fly makes it possible for birds to disperse into suitable habitats after destruction of their original habitats. Conversely, tropical primate species have small geographical ranges and their dispersal ability is low; therefore they may not survive massive habitat loss like that in North America in the past 2 centuries.

\section{Response of Primate Populations to Exotic Plant Species}

Though researchers have reported no direct severe consequences of introduced plant species on primate populations, we must remain vigilant because such plants can have indirect negative impacts. Historically, people have moved plants from one continent to another. In Uganda, tree species such Eucalyptus spp., Sena (Cassia) spectablis, and the black wattle (Acacia mearnsii) are not indigenous but are common in some parts of the country including protected areas. Species such as Eucalyptus that seem not to germinate without human intervention may not be much of a problem because it is easy to remove them. However, some e.g., Sena spectabilis and Acacia mearnsii, can be invasive and take over gaps in natural forests, thus interfering with the regeneration of indigenous trees. In Semulik National Park and several forest reserves in western Uganda, Sena spectablis is a very common tree species while in Kibale it is restricted to small areas but may spread if not checked. In Mghinga National Park, Acacia mearnsii is believed to potentially invasive (Lejju et al. 2001). In Mabira Forest Reserve, southeast Uganda, and in Budongo Forest, western Uganda, the paper mulberry tree, a highly invasive tree species, dominates many gaps and lands encroachers abandoned in the early 1990s (pers. obs.). Even trees that are indigenous at the continental scale may cause environmental problems when introduced in localities where they do not occur naturally. For example, Maesopsis eminii is an African tree, but there is concern that it may disrupt the forest ecosystem in the Usambara Mountains, Tanzania where it was introduced in the late 1800s (Hall 1995).

Forest gaps and the forest edge are important sites for forest regeneration (Clark 1990), but invasive plant species perform best in the microhabitats, thereby competing with the native species. Some invasive plant species such as the paper mulberry and Maesopsis produce fruit that is edible to primates, which may seem beneficial. For example, the fruit of the mulberry tree has become an important food for chimpanzees in Budongo Forest (Bakuneeta 2001). Nonetheless, not all primates are frugivores, which means that frugivores may benefit at the expense of folivores, and by competing and excluding native tree species, exotics can disrupt the stability of fruit supply in the forest because they do not fruit all year round. Should they exclude keystone species such as figs, then the consequences to primate survival will be very severe. Patches of preferred introduced species can attract large numbers of primate groups in the area. For example, at Kanyawara, black-and-white colobus and 
red colobus have adapted to eating leaves and bark from Eucalyptus, an introduced species, and their group densities are high in and around the plantations. The situation appears to lead to increased intensity of intergroup aggression resulting from competition for access to the Eucalyptus patch, particularly in black-and-white colobus (Harris and Chapman 2007).

\section{Responses of Primate Populations to Natural Changes}

\section{Tree Dieback}

Extensive tree diebacks can have negative effects on populations of primate species that depend on them for food. In fact, such negative effects can be comparable to those of selective logging if a wide range of tree species is involved. At the Kanyawara study area, Kibale Forest, Struhsaker et al. (1989) observed a dieback involving 5 canopy tree species. The level of mortality was variable; by $1986,100 \%$ of Newtonia buchananii, 90\% of Lovoa swynnertonii, and 45\% of Aningeria altissima were dead in the affected area. For the other 2 species, Mimusops bagshwawei and Celtis africana, mortality was only $0.5 \%$ and $1.6 \%$, respectively. However, anecdotal observations since the study by Struhsaker suggest that mortality among Celtis africana has increased. The tree species affected by the dieback were important food sources for red colobus (Struhsaker 1975). Table 1 contains percentage contributions of each tree species to the food intake of Struhsaker's study group during 19 mo.

The data in Table 1 clearly indicate the importance of the tree species in the red colobus diet, with some trees such as Newtonia buchananii contributing $\geq 6 \%$ of the feeding scores in any 1 mo during the study, and Celtis africana contributing up to $38 \%$ in some months. Diebacks of such important food tree sources as occurred in Kanyawara will definitely affect the ranging patterns and possibly food intake of the monkeys. The dieback occurred in the old growth forest and may explain the decline in red colobus abundance (as the monkeys expanded home ranges in search for food) in the part of the forest Chapman et al. (2000) studied.

\section{Climatic Change}

Though the impact of past climatic change is not clearly understood, particularly with regard to forest composition and patchiness, there is evidence to suggest that it is already affecting primate habitats and hence primate populations (Chapman et al.

Table 1 Tree species affected by dieback, range, and mean monthly food intake by a group of red colobus during 19 mo of observations

Data source: Struhsaker (1975).

\begin{tabular}{lcl}
\hline Tree species & Mean monthly (\%) & Range (\%) \\
\hline Aningeria altissima & $6.8+7.8$ & $0-25$ \\
Celtis Africana & $9.4+11.8$ & $0-38$ \\
Lovoa swynnertonii & $2.0+3.3$ & $0-11$ \\
Newtonia buchannanii & $10.5+4.07$ & $6.2-16.3$ \\
\hline
\end{tabular}


2005a, b). Scientists have predicted that global warming will result in decreased rainfall and longer dry seasons in some tropical rain forests (Borchert 1998). The interval between El Niño events, which are intricately linked to global warming, has declined drastically from $c a$. 400-700 yr to only 3-7 yr (Laurence and Williamson 2001). In the wet tropics, El Niño events are associated with high levels of tree mortality among canopy trees (Holmgren et al. 2001; Laurence and Williamson 2001). Therefore, climatic change can have severe effects on the food resource base for primates. If the scenarios materialize, we should then expect reduced forest cover and increased forest patchiness. We therefore need to collect long-term data on various ecological aspects of primates such as group size and composition, ranging patterns, and diet to monitor potential impacts of climatic change on primates.

Climatic change will most likely aggravate the negative impacts of human induced changes to forest habitats, thus harming the primates further. For example, in the Amazon, small forest fragments and logged forests are more vulnerable to fires during droughts than intact forests are (Laurence and Williamson 2001). This can be true for other areas because everywhere, logging creates a thick layer of combustible material on the forest floor. In general, logging concessions cover several hundreds of hectares of forest, which means, in case of fire, the heat will kill many resident primates. Even if they escape, it is likely that they may die of starvation because forest trees are not fire resistant. With elevated temperatures and prolonged droughts, tree mortality is expected to increase in fragmented forests. In the Amazon, drought-related tree mortality was highest in small fragments (Laurence and Williamson 2001).

Acknowledgments We thank John Mitami, David Watts, and Colin Chapman for their comments on earlier versions of the manuscript.

\section{References}

Bakuneeta, C. (2001). Ecology and behaviour of chimpanzees in Budongo Forest, Uganda. Ph.D. thesis, Makerere University.

Borchert, L. (1998). Responses tropical trees to rainfall seasonality and long-term changes. Climatic Change, 39, 381-393.

Chapman, A., Balcomb, S. R., Gillespie, T. R., Skorupa J. P., \& Struhsaker, T. T. (2000). Long-term effects of logging on African primate communities: A 28-year comparison from Kibale National Park, Uganda. Conservation Biology, 14, 207-217.

Chapman, C. A., Chapman, L. J., \& Gillespie, T. R. (2002). Scale issues in the study of primate foraging: Red colobus of Kibale National Park. American Journal of Physical Anthropology, 117, 349-363.

Chapman, C. A., Chapman, L. J., Struhsaker, T. T., Zanne, A. E., Clark, C. J., \& Poulsen, J. R. (2005a). A long-term evaluation of fruit phenology: Importance of climate change. Journal of Tropical Ecology, $21,35-45$.

Chapman, C. A., Chapman, L. J., Vulinec, K., Zanne, A., \& Lawes, M. J. (2003). Fragmentation and alteration of seed dispersal processes: An initial evaluation of dung beetles, seed fate, and seedling diversity. Biotropica, 35, 382-393.

Chapman, C. A., Chapman, L. J., Zanne, A. E., Poulsen, J. R., \& Clark, C. J. (2005b). A 12-year phenological record of fruiting: Implications for frugivore populations and indicators of climate change. In J. L. Dew \& J. P. Boubli (Eds.), Tropical fruits and frugivores (pp. 75-92). The Netherlands: Springer.

Chapman, C. A., Lawes, M. J., \& Eeley, H. A. C. (2006a). What hope for African primate diversity? African Journal of Ecology, 44, 116-133.

Chapman, C. A., \& Peres, C. A. (2001). Primate conservation in the new millennium: The role of scientists. Evolutionary Anthropology, 10, 16-33. 
Chapman, C. A., Speirs, M. S, Gillespie, T. R., Holland, T., \& Austad, K. M. (2006c). Life on the edge: Gastrointestinal parasites from the forest edge and Interior primate groups. American Journal of Primatology, 68, 397-409.

Chapman, C. A., Wasserman, M. D., Gillespie, T. R., Speirs, M., Lawes, M. J., Saj, T. L., et al. (2006b). Do food availability, parasitism, and stress have synergistic effects on red colobus populations living in forest fragments? American Journal of Physical Anthropology, 131, 525-534.

Clark, D. B. (1990). The role of disturbance in the regeneration of Neotropical moist forest. In K. S. Bawa \& M. Hadley (Eds.), Reproductive ecology of tropical forest plants (pp. 291-315). Paris: UNESCO.

Cowlishaw, G. (1999). Predicting the pattern of decline of African primate diversity: An extinction debt from historical deforestation. Conservation Biology, 13, 1183-1193.

DeWalt, S. J., Maliakal, S. K., \& Denslow, J. S. (2003). Changes in vegetation structure and composition along a tropical chronosequence: Implications for wildlife. Forest Ecology and Management, 182, $139-151$.

Fairgrieve, C., \& Muhumuza, G. (2003). Feeding ecology and dietary differences between blue monkey (Cercopithecus mitis stuhlmanii Matschie) groups in logged and unlogged forest, Budongo Forest Reserve, Uganda. African Journal of Ecology, 41, 141-149.

Fedigan, L. M., \& Jack, K. (2001). Neotropical primates in a regenerating Costa Rican dry forest: A comparison of howler and capuchin population patterns. International Journal of Primatology, 22, 689-713.

Gillespie, T. R., \& Chapman, C. A. (2006). Prediction of parasite infection dynamics in primate metapopulations based on attributes of forest fragmentation. Conservation Biology, 20, 441-448.

Hall, J. B. (1995). Maesopsis eminii and its status in the East Usambara Mountains. EUCFP Technical Report No. 13, 41 pp.

Harris, T. R., \& Chapman, C. A. (2007). Variation in diet and ranging of black and white colobus monkeys in Kibale National Park, Uganda. Primates, 48, 208-221.

Holmgren, M., Scheffer, M., Ezcurra, E., Gutierrez, J. R., \& Mohrem, G. M. J. (2001). El Nino effects on the dynamics of terrestrial ecosystems. Trends in Ecology and Evolution, 16, 89-94.

Johns, A. D. (1992). Vertebrate responses to selective logging: Implications for the design of logging systems. Philosophical Transactions of the Royal Society of London B-Biological Sciences, 335, $437-442$.

Johns, A. D., \& Skorupa, J. P. (1987). Responses of rainforest primates to habitat disturbance: A review. International Journal of Primatology, 8, 157-191.

Karlowiski, U. (2006). Afromontane old-field vegetation: Secondary succession and the return of indigenous species. African Journal of Ecology, 44, 264-272.

Kasenene, J. M. (1987). The influence of mechanized selective logging, felling intensity, and gap-size on the regeneration of moist tropical forest in Kibale Forest Reserve, Uganda. Ph.D. thesis, Michigan State University, East Lansing.

Laurence, W. F., \& Williamson, G. B. (2001). Positive feedbacks among forest fragmentation, droughts, and climate change in the Amazon. Conservation Biology, 15, 1529-1535.

Lawes, M. J. (2002). Conservation of fragmented populations of Cercopithecus mitis. In South Africa: The role of reintroduction, corridors and metapopulation ecology. In: M. Glenn \& M. Cords (Eds.), The Guenons: Diversity and adaptation in African monkeys (pp. 375-392). New York: Kluwer Academic/ Plenum Publishers.

Lawes, M. J., \& Chapman, C. A. (2006). Does the herb Acanthus pubescens and/or elephants suppress tree regeneration in disturbed Afrotropical forest? Forest Ecology and Management, 221, 278-284.

Lejju, J. B., Oryem-Origa, H., \& Kasenene, J. M. (2001). Regeneration of indigenous trees in Mgahinga Gorilla National Park, Uganda. African Journal of Ecology, 39, 65-73.

Leroy, E. M., Rouquet, P., Formenty, P., Souquiere, S., Kilbourne, A., Forment, J.-M., et al. (2004). Multiple Ebola virus transmission events and rapid decline of central African wildlife. Science, 303, 387.

Lovett, J. C., \& Marshall, A. R. (2006). Why should we conserve primates? African Journal of Ecology, $44,113-115$.

Lwanga, J. S. (2003). Forest succession in Kibale National Park, Uganda: Implications for forest restoration and management. African Journal of Ecology, 41, 9-22.

Lwanga, J. S. (2006). Spatial distribution of primates in a mosaic of colonizing and old growth forest at Ngogo, Kibale National Park. Primates, 47, 230-238.

Masmbuko, E. (2005). Mengo opposes Mabira sale. Daily Monitor, November 16, 2005.

Michalski, F., \& Peres, C. A. (2005). Anthropogenic determinants of primate and carnivore local extinctions in a fragmented forest landscape of southern Amazonia. Biological Conservation, 124, 383-396. 
Mitani, J. C., \& Amsler, S. (2003). Social and spatial aspects of male subgrouping in a community of chimpanzees. Behaviour, 140, 869-884.

Mitani, J. C., Struhsaker, T. T., \& Lwanga, J. S. (2000). Primate community dynamics in old growth forest over 23.5 years at Ngogo, Kibale National Park, Uganda: Implications for conservation and census methods. International Journal of Primatology, 21, 269-286.

Mittermeier, R. A., \& Cheney, D. L. (1987). Conservation of primates and their habitats. In B. B. Smuts, D. L. Cheney, R. M. Seyfarth, R. W. Wrangham, \& T. T. Struhsaker (Eds.), Primate societies (pp. 475-490). Chicago: Chicago University Press.

Nummelin, M. (1990). Relative habitat use of duikers, bush pigs, and elephants in virgin and selectively logged areas of Kibale Forest, Uganda. Tropical Zoology, 3, 111-120.

Oates, J. F. (1974). The ecology and behaviour of the black-and-white colobus monkey (Colobus guereza Ruppell) in East Africa. Ph.D. thesis, University of London.

Paterson, J. D. (1991). The ecology and history of Uganda's Budongo Forest. Forest and Conservation History, 35, 179-186.

Paul, J. R., Randle, A. M., Colin, A., Chapman, C. A., \& Chapman, L. J. (2004). Arrested succession in logging gaps: Is tree seedling growth and survival limiting? African Journal of Ecology, 42, 245-251.

Peeters, M. (2004). Cross-species transmission of simian retroviruses in Africa and risk for human health. The Lancet, 363, 911-912.

Plumptre, A. J. (1996). Changes following 60 years of selective timber harvesting in the Budongo Forest Reserve, Uganda. Forest Ecology and Management, 89, 101-113.

Plumptre, A. J., \& Reynolds, V. (1994). The effects of selective logging on the primate populations in the Budongo Forest Reserve, Uganda. Journal of Applied Ecology, 31, 631-641.

Reynolds, V. (2006). Threats to, and protection of, the chimpanzees of the Budongo Forest Reserve. In N. E. Newton-Fisher, H. Notman, J. D. Paterson, \& V. Reynolds (Eds.), Primates of Western Uganda (pp. 391-403). New York: Springer.

Rouquet, P., Froment, J-M., Bermejo, M., Kilbourn, A., Karesh, W., Reed, P., et al. (2005). Wild animal mortality monitoring and human Ebola outbreaks, Gabon, and Republic of Congo, 2001-2003. Emerging Infectious Diseases, 11, 283-290.

Sharp, P. M., Shaw, G. M., \& Hahn, B. H. (2004). Simian immunodeficiency virus infection of chimpanzees. Journal of Virology, 79, 3891-3902.

Simberloff, D. (1992). Do species-area curves predict extinction in fragmented forest? In T. C. Whitmore \& J. A. Sayer (Eds.), Tropical deforestation and species extinction (pp. 75-89). London: Chapman \& Hall.

Skorupa, J. P. (1986). Responses of rainforest primates to selective logging in Kibale Forest, Uganda. In Primates: K. Benirschke (Ed.) The road to self-sustaining populations (pp. 57-70). New York: Springer-Verlag.

Struhsaker, T. T. (1975). The red Colobus monkey. Chicago: University of Chicago Press.

Struhsaker, T. T. (1978). Food habits of five monkey species in the Kibale Forest, Uganda. In D. Chivers \& J. Herbert (Eds.), Recent advances in primatology (pp. 225-248). London: Academic Press.

Struhsaker, T. T. (1981). Forest and primate conservation in East Africa. African Journal of Ecology, 19, 99-114.

Struhsaker, T. T. (1997) Ecology of an African rain forest. Gainesville: University Press of Florida.

Struhsaker, T. T., Kasenene, J. M., Gaither Jr., J. C., Larsen, N., Musango, S., \& Bancroft, R. (1989). Tree mortality in the Kibale Forest, Uganda: A case study of dieback in a tropical rain forest adjacent of exotic conifer plantations. Forest Ecology and Management, 29, 165-185.

Struhsaker, T. T., Lwanga, J. S., \& Kasenene, J. M. (1996). Elephants, selective logging and the regeneration in the Kibale Forest, Uganda. Journal of Tropical Ecology, 12, 45-64.

Teelen, S. (2005). The impact of hunting by chimpanzees (Pan troglodytes) on demography and behavior of red colobus monkeys (Procolobus ruformitratus) at Ngogo, Kibale National Park, Uganda. Ph.D. dissertation, New Haven, CT: Yale University.

Twinomugisha, D. (2007). Conservation status and determinants of golden (Cercopithecus mitis kandti) abundance in Mgahinga National Park. Ph.D. thesis Makerere, University.

Vogel, G. (2003). Can great apes be saved from Ebola? Science, 300, 1645.

Watts, D. P., \& Mitani, J. C. (2001) Boundary patrols and intergroup encounters in wild chimpanzees. Behaviour, 138, 299-327.

Watts, D. P., Muller, M., Amsler, S. J., Mbabazi, G., \& Mitani, J. C. (2006). Lethal intergroup aggression by chimpanzees in Kibale National Park, Uganda. American Journal of Primatology, 68, 161-180.

Wolfe, D. N., Switzer, W. M., Carr, J. K., Bhullar, V. B., Shanmugan, V., Tamoufe, U., et al. (2004). Naturally acquired simian retrovirus infections in central African hunters. The Lancet, 363, 932-937. 